\title{
The Impact of Increased Penetration of Converter Control Based Generators on Power System Modes of Oscillation
}

\author{
Jaime Quintero Member, IEEE, Vijay Vittal, Fellow, IEEE, Gerald Thomas Heydt, Life Fellow, IEEE \\ and Hui Zhang, Student Member
}

\begin{abstract}
The impact of increasing penetration of converter control based generators (CCBGs) in a large-scale power system is assessed through a model based small signal stability analysis. Three test bed cases for the years 2010, 2020 and 2022 of the Western Electricity Coordinating Council (WECC) in the United States are used for the analysis. Increasing penetration of wind-based Type 3 and wind-based Type 4 and PV Solar CCBGs is used in the tests. The participation and interaction of CCBGs and synchronous generators in traditional electromechanical interarea modes is analyzed. Two new types of modes dominated by CCBGs are identified. The characteristics of these new modes are described and compared to electromechanical modes in the frequency domain. An examination of the mechanism of the interaction between the CCBG control states and the synchronous generator control states is presented and validated through dynamic simulations. Actual system and forecast load data are used throughout.
\end{abstract}

Index Terms-Small signal stability, modal analysis, full converter control-based generator, doubly fed induction generator wind turbine, full-converter wind turbine, PV solar generation, transmission systems.

\section{INTRODUCTION}

$\mathrm{D}$ URING the last decade, the popularization of wind turbine technology including variable-speed doubly fed asynchronous generators (DFAGs) and full converter control based generators (FCCBGs) have replaced the older constant-speed squirrel cage induction generators in new wind power installations. Additionally, current utility scale photovoltaic (PV) plants are full converter control based systems. Therefore, the impact of the increasing penetration level of these new converter control based generators (CCBGs) on the security and reliability of the power system has been the subject of recent research [1-6].

Since the mechanical dynamics of CCBGs is completely decoupled from the electric grid, they primarily only have four mechanisms by which they can affect the damping of electromechanical modes (since they themselves do not participate in

This work is supported in part by the U.S. Department of Energy funded project denominated "Regional Transmission Expansion Planning in the Western Interconnection" under contract DOE-FOA0000068. This is a project under the American Recovery and Reinvestment Act.

J. Quintero, V. Vittal, G. T. Heydt and H. Zhang are with the Department of Electrical Engineering, Arizona State University, Tempe, AZ 85287 USA (e-mail: jaime.quintero.1@asu.edu, vijay.vittal@asu.edu, heydt@asu.edu hui.zhang@asu.edu). Jaime Quintero is on leave of absence from Universidad Autónoma de Occidente, Cali, Colombia. the modes) [4-9]:

1. Displacing synchronous machines thereby affecting the modes

2. Impacting major path flows thereby affecting the synchronizing forces

3. Displacing synchronous machines that have power system stabilizers

4. CCBG controls interacting with the damping torque on large synchronous generators

In particular, in the case of the small signal stability problem, some efforts have focused on the collateral impact of CCBGs displacing conventional synchronous generators with power system stabilizers (PSSs) and also on the effect of reducing the overall inertia of the system [4]. The probabilistic nature of wind power and the potential effect on the small signal stability of the overall system has been addressed in [5]. Some other studies have addressed the modal characteristics of the CCBGs and their potential effects on the modal behavior of the power system, using a single machine infinite bus approach [7] or a reduced power system test bed case [6], [8] and [9]. It has been found also that, complementary control loops in CCBGs may be effective in providing additional damping to traditional electromechanical modes [9-10]. Therefore, some supplementary control loop solutions have been presented for emulating inertia response [11] and PSS [12] for CCBGs.

The aim of this paper is to contribute to the analysis of the direct modal impact of increased penetration levels of CCBGs, including DFAGs and full converter based generators (both wind and PV), on large-scale power systems. The primary emphasis in this work deals with exploring the fourth mechanism by which CCBGs impact electromechanical modes and to examine other oscillatory modes associated primarily with CCBG state variables. The direct participation of CCBG state variables in the transformation of the main electromechanical interarea modes of the Western Electricity Coordinating Council (WECC) system with increasing penetration levels is evaluated. The identification and characterization of two new kind of oscillatory modes dominated by CCBG state variables is presented. Also, the interaction between CCBG control state variables and synchronous generators control state variables in these new types of modes is described. 
The three test bed cases used in this work are described in Table I. They were obtained from WECC which encompasses approximately the western one-third of the United States. The first case is an operating case representing heavy summer conditions of the Western Interconnection in the year 2010. The two other cases are horizon studies representing heavy summer conditions for year 2020 and light spring conditions for year 2022. As seen in Table I, the planned cases include numerous updates to the transmission, generation and load. Notice that CCBGs supply an increasing level of $0 \%, 2.74 \%$ and $13.2 \%$ of the total in-service active power generation in cases 2010, 2020 and 2022 respectively. CCBGs are represented in the test bed cases mostly as generic models as described in [13], but there is $6.12 \%$ in the 2020 case and $20.22 \%$ in the 2022 case of the total in-service CCBG generation represented by General Electric (GE) models [14-15]. Type 3 doubly fed induction generators (DFIG) or DFAG models for representing wind farms and Type 4 full converter control based generators for representing wind farms and utility scale photovoltaic (PV) systems. They are represented operating at different control configurations but without supplementary control loops. The cases analyzed represent large planning cases with all the conventional models of synchronous generators and associated controls represented. The HVDC systems in the WECC are also incorporated. The composite load model is also included as per the WECC criterion for the representation of detailed loads [16].

TABLE I WECC TEST BED CASES

\begin{tabular}{lrrr}
\hline \hline & $\begin{array}{c}\text { Heavy summer } \\
\text { 2010 case }\end{array}$ & $\begin{array}{c}\text { Heavy summer } \\
\text { 2020 case }\end{array}$ & $\begin{array}{c}\text { Light spring } \\
\text { 2022 case }\end{array}$ \\
\hline Buses & 16,791 & 17,530 & 19,745 \\
Generators & 3,346 & 3,885 & 4,461 \\
Loads & 8,284 & 8,590 & 9,147 \\
Shunts & 1,279 & 1,508 & 1,621 \\
Static VAR & 973 & 1,043 & 1,148 \\
Devices (SVDs) & 12 & 20 & 22 \\
DC buses & 174,316 & 178,037 & 121,306 \\
Generation & $+j 23,516$ & $+j 11,231$ & $+j 2,989$ \\
(MVA) & 0 & Type $3: 2,647$ & Type $3: 7,217$ \\
CCBG Genera- & & Type $4: 2,224$ & Type $4: 8,800$ \\
tion (MW) & 168,254 & 172,634 & 117,137 \\
Load (MVA) & $+j 31,591$ & $+j 36,287$ & $+j 27,278$ \\
Shunt (MVAr) & $j 13,112$ & $j 19,452$ & $j 7,308$ \\
SVD (MVAr) & $j 16,217$ & $j 8,961$ & $j 2,228$ \\
\hline \hline
\end{tabular}

Hence, the nature of the analysis conducted is unique in terms of the size of the system considered. Additionally even though a conventional commercial small-signal stability analysis tool SSAT [17] is used to conduct the analysis, the unique contributions of this work are:

i) the identification of a hitherto undocumented mode of oscillation involving state variables of only CCBG units and in a frequency range akin to electromechanical oscillations of conventional synchronous generators,

ii) a low frequency oscillation mode involving both state variables of CCBGs and conventional synchronous generators with the interaction occurring primarily through control state variables,

iii) analysis and determination of the mechanism of interaction of the control variables and the impact of this interaction on the system dynamic behavior.

The remainder of the paper is organized as follows: Section II presents the fundamental basis of the model based small signal stability analysis used in this work. Section III describes the frequency response of the main electromechanical interarea modes of the Western Interconnection through the three test bed cases, assessing the participation of CCBGs in these modes. With the increasing penetration level of CCBGs two new kinds of modes are identified and characterized in Section IV. Results and analysis are provided throughout these sections. Concluding remarks are presented in Section V.

\section{Fundamentals of THE SMALl Signal Stability ANALYSIS}

Mathematically, a power system is modeled by a set of nonlinear first order ordinary differential equations that represent the dynamic components of the system, and a set of algebraic equations that represent the quasi-static behavior of the transmission network. Thus, the state space representation of a power system maybe written as a differential-algebraic model

$$
\dot{\mathbf{x}}=\mathbf{f}(\mathbf{x}, \mathbf{w}), \quad \mathbf{0}=\mathbf{g}(\mathbf{x}, \mathbf{w})
$$

Bold face symbols refer to vectors and matrices. From the Taylor series expansion around $\left(\mathbf{x}_{\mathbf{0}}, \mathbf{w}_{\mathbf{0}}\right)$, the linearized model is given by

$$
\Delta \dot{\mathbf{x}}=\mathbf{A} \Delta \mathbf{x}+\mathbf{B} \Delta \mathbf{w}, \quad \mathbf{0}=\mathbf{C} \Delta \mathbf{x}+\mathbf{D} \Delta \mathbf{w}
$$

where,

$$
\begin{array}{ll}
\mathbf{A}=\frac{\partial \mathbf{f}}{\partial \mathbf{x}}\left(\mathbf{x}_{0}, \mathbf{w}_{0}\right), & \mathbf{B}=\frac{\partial \mathbf{f}}{\partial \mathbf{w}}\left(\mathbf{x}_{0,} \mathbf{w}_{0}\right), \\
\mathbf{C}=\frac{\partial \mathbf{g}}{\partial \mathbf{x}}\left(\mathbf{x}_{0,}, \mathbf{w}_{0}\right), & \mathbf{D}=\frac{\partial \mathbf{g}}{\partial \mathbf{w}}\left(\mathbf{x}_{0,} \mathbf{w}_{0}\right) .
\end{array}
$$

Assuming that the equilibrium point does not coincide with the singularity of the network equations, (2) can be written as

$$
\Delta \dot{\mathbf{x}}=\mathbf{J} \Delta \mathbf{x}, \quad \text { where } \mathbf{J}=\mathbf{A}-\mathbf{B D}^{-1} \mathbf{C}
$$

Therefore, stability in the sense of Lyapunov may be established by the sufficient conditions on the eigenvalues of matrix $\mathbf{J}$ [18]. An eigenvalue of the square matrix $\mathbf{J}$ is defined as the real or complex number $\lambda$ such that [19-20] 


$$
\begin{aligned}
& \mathbf{J u}=\lambda \mathbf{u} \\
& \mathbf{v J}=\lambda \mathbf{v}
\end{aligned}
$$

Any nonzero $n$-column vector $\mathbf{u}$ satisfying (4) is called a right eigenvector of $\mathbf{J}$ associated with $\lambda$. Similarly, any nonzero $n$-row vector $\mathbf{v}$ which satisfies (4) is called a left eigenvector of $\mathbf{J}$ associated with $\lambda$. There are $n$ real or complex eigenvalues associated with $\mathbf{J}$, consider in this section the case of having all distinct eigenvalues. Therefore, there are $n$ right and $n$ left independent eigenvectors associated with the $n$ distinct eigenvalues of $\mathbf{J}$, and they can be normalized such that the right and left eigenvectors associated with the $i$ eigenvalue are

$$
\mathbf{v}_{i} \mathbf{u}_{i}=1 \quad \text { for } \quad i=1,2, \ldots, n
$$

The right and left modal matrices $\mathbf{U}=\left[\begin{array}{llll}\mathbf{u}_{1} & \mathbf{u}_{2} & \ldots & \mathbf{u}_{n}\end{array}\right]$ and $\mathbf{V}=\left[\begin{array}{llll}\mathbf{v}_{1}{ }^{T} & \mathbf{v}_{2}{ }^{T} & \ldots & \mathbf{v}_{n}{ }^{T}\end{array}\right]^{T}$ are such that, $\mathbf{V}=\mathbf{U}^{-1}$.

The right eigenvectors are used particularly for determining the mode shape. In other words, what components of the power system exhibit the selected mode's frequency response and how they interact with each other [21]. As stated in [22], the net associations between state variables and natural modes of matrix $\mathbf{J}$ can be ascertained from the participation matrix $\mathbf{P}$. This matrix is obtained by a term by term multiplication between the elements of the right and left modal matrices such as, the $k i^{\text {th }}$ element of matrix $\mathbf{P}$ is obtained as,

$$
p_{k i}=u_{k i} v_{i k}
$$

Here the participation factor $p_{k i}$ is the $k, i$ element of $\mathbf{P}$ and gives the net participation of the $k^{\text {th }}$-state in the $i^{\text {th }}$-mode and vice versa. The participation factor is a dimensionless quantity [22].

\section{THE IMPACT OF CCBGS ON TRADITIONAL ELECTROMECHANICAL INTERAREA MODES}

In order to assess the impact of the increasing levels of CCBGs in cases 2020 and 2022 on traditional electromechanical interarea modes, the main interarea electromechanical modes in the WECC system were identified in cases 2010, 2020 and 2022 using SSAT [17]. Also, the participation of CCBGs in these modes was determined through a CCBG participation index (CCBG PI). The index associated with mode $i$ is obtained considering only participation factors greater than 0.1 and is defined as,

$$
\text { CCBGPI }=\frac{\sum^{C C B G} p_{k i}}{\sum^{A l l} p_{k i}} \quad \text { for mode } i
$$

where the numerator is the summation of the participation factors of all state variables associated with CCBGs affecting mode $i$ and larger than 0.1, and the denominator is the summation of the participation factors of all the state variables associ- ated with mode $i$ and greater than 0.1 . It is often useful to retain the numerator and denominator information in the CCBG PI as given in (8).

Tables II, III and IV show the identified electromechanical interarea modes for test bed cases 2010, 2020 and 2022 respectively. All modes were carefully identified comparing mode shapes and participation factors. Also the mode type indices and the comparison indices provided by SSAT [17] were useful in this task. The mode type index provides information on the number of generators whose speeds in mode shape are larger than a threshold and therefore, it is useful for identifying interarea electromechanical modes. The comparison index is a normalized index, comparing the mode shapes of selected modes against a reference mode shape, then providing a value between zero and one about the similarity of the selected modes with respect to the reference. The number of areas in the mode shape and the number of generators with participation factors greater than 0.1, are included in the tables. Note that most of the identified modes in case 2010 undergo significant changes in cases 2020 and 2022, in terms of frequency, damping ratio and participating areas. Modes 5 and 6 vanish in case 2020 and mode 3 is not present in case 2022.

TABLE II

MAIN ELECTROMECHANICAL INTERAREA MODES IN THE 2010 CASE

\begin{tabular}{c|ccccc}
\hline \hline Mode & $\begin{array}{c}f \\
(\mathbf{H z})\end{array}$ & $\begin{array}{c}\zeta \\
(\%)\end{array}$ & CCBG PI* & $\begin{array}{c}\text { Number } \\
\text { of Areas }\end{array}$ & $\begin{array}{c}\text { Number } \\
\text { of Gen }\end{array}$ \\
\hline 1 & 0.23 & 12.3 & $0 / 39.9$ & 5 & 76 \\
\hline 2 & 0.34 & 9.9 & $0 / 25.8$ & 5 & 54 \\
\hline 3 & 0.81 & 11.1 & $0 / 50.7$ & 10 & 87 \\
\hline 4 & 0.52 & 14.2 & $0 / 83$ & 11 & 128 \\
\hline 5 & 0.61 & 12.6 & $0 / 58.3$ & 14 & 103 \\
\hline 6 & 0.64 & 11.3 & $0 / 36.4$ & 8 & 50 \\
\hline
\end{tabular}

*The numerator and denominator in (8) are preserved and indicated in this column

TABLE III

MAIN ELECTROMECHANICAL INTERAREA MODES IN THE 2020 CASE

\begin{tabular}{c|ccccc}
\hline \hline Mode & $\begin{array}{c}f \\
(\mathbf{H z})\end{array}$ & $\begin{array}{c}\zeta \\
(\boldsymbol{\%})\end{array}$ & CCBG PI* & $\begin{array}{c}\text { Number } \\
\text { of Areas }\end{array}$ & $\begin{array}{c}\text { Number } \\
\text { of Gen }\end{array}$ \\
\hline 1 & 0.25 & 19.5 & $2.6 / 49.3$ & 6 & 94 \\
\hline 2 & 0.37 & 10.9 & $0.6 / 7.2$ & 3 & 6 \\
\hline 3 & 0.88 & 11.2 & $0 / 69.7$ & 10 & 125 \\
\hline 4 & 0.54 & 9.4 & $0.5 / 36.8$ & 7 & 63 \\
\hline 5 & -- & -- & -- & -- & -- \\
\hline 6 & -- & -- & -- & -- & - \\
\hline \hline
\end{tabular}

*The numerator and denominator in (8) are preserved and indicated in this column 
TABLE IV

MAIN ELECTROMECHANICAL INTERAREA MODES

IN THE 2022 CASE

\begin{tabular}{c|ccccc}
\hline \hline Mode & $\begin{array}{c}f \\
(\mathbf{H z})\end{array}$ & $\begin{array}{c}\zeta \\
(\boldsymbol{\%})\end{array}$ & CCBG PI* & $\begin{array}{c}\text { Number } \\
\text { of Areas }\end{array}$ & $\begin{array}{c}\text { Number } \\
\text { of Gen }\end{array}$ \\
\hline 1 & 0.31 & 19.7 & $0 / 73.2$ & 7 & 97 \\
\hline 2 & 0.47 & 12.2 & $0 / 4.4$ & 3 & 4 \\
\hline 3 & -- & -- & -- & -- & -- \\
\hline 4 & 0.62 & 5.92 & $0.9 / 30.1$ & 6 & 71 \\
\hline 5 & 0.67 & 13.4 & $0 / 10.2$ & 4 & 16 \\
\hline 6 & 0.84 & 9.4 & $0 / 31.3$ & 9 & 65 \\
\hline \hline
\end{tabular}

*The numerator and denominator in (8) are preserved

It is important to note that the participation of CCBG state variables in these modes is very small, as indicated by the CCBG PI. The accumulated participation is zero in most of the modes and relatively small in some of them. This is expected in cases 2010 and 2020 where the active power generation provided by CCBGs accounts for $0 \%$ and $2.74 \%$ of the total active power generation. However, this is not the situation in case 2022 where $13.20 \%$ of the total active power generation is supplied by CCBGs. Also, it was found that the only participating CCBGs in the case 2020 are generic Type 3 models operating in constant reactive power control mode. In these cases the reference value $Q_{\text {ref }}$ is set to match the initial reactive power output of the generator and is held constant as shown in Fig. 1. Whereas in case 2022 the participating CCBGs are generic Type 4 models operating in reactive control output priority with wind plant reactive control emulation, as shown in Fig. 2. The control parameters associated with the participating CCBG state variables are the reactive power control integral gains $K_{\mathrm{qi}}$ and the voltage control integral gains $K_{\mathrm{qv}}$ and $K_{\mathrm{vi}}$, shown in Figures 1 and 2 .

From Tables II to IV, it is clear that with the very low participation of CCBGs state variables in the identified electromechanical modes, the significant changes in the frequency response are not a direct consequence of the action of CCBGs operating under the conditions described above. These changes are due mostly by the numerous updates to the transmission, generation and load as presented in Table I, impacting flow paths and participating generators. The change in the number of participating generators can be seen also in Tables II to IV.

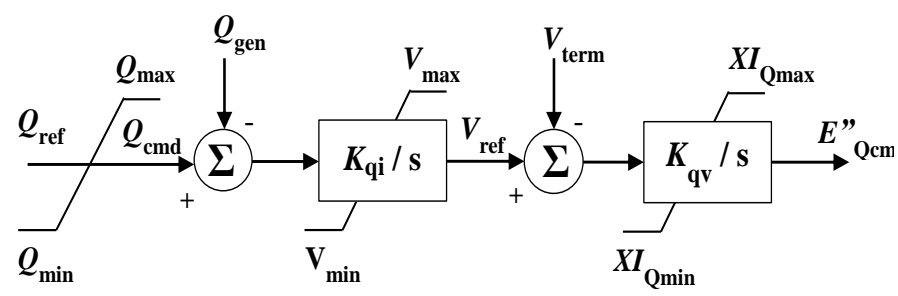

Fig. 1. Generic Type 3 reactive power control model of participating CCBGs. Note that the generator is operating in constant reactive power control mode.

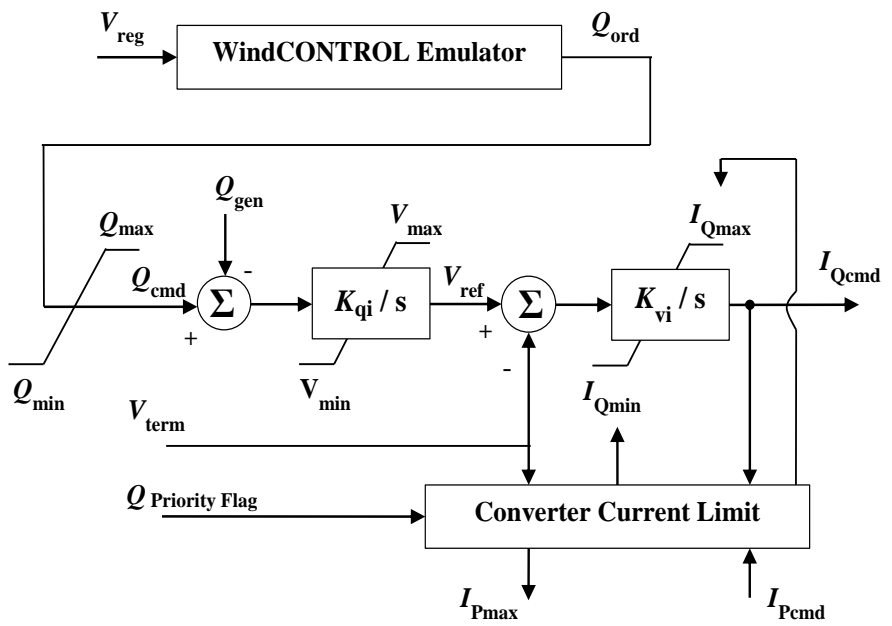

Fig. 2. Generic Type 4 electrical control model of participating CCBGs. Note that the generator is operating in reactive control output priority with wind plant reactive control emulation mode.

\section{NEW CCBG OSCILlatory MODES}

This section introduces two types of newly identified oscillatory modes dominated mostly by CCBGs. These modes are presented in Table V. It is important to observe that these modes of a frequency of oscillation in the same range as an interarea electromechanical mode of oscillation. Some of these modes also happen to be poorly damped. One important difference between these modes and conventional electromechanical modes introduced in Section III is that the identified CCBG oscillatory modes do not involve a large number of participating state variables. This phenomenon is seen by comparing the magnitude of the denominator of the CCBG PI in Table V versus the denominators of the CCBG PI in Tables II, III and IV. Notice that here, as well as in the electromechanical modes in Section III, the CCBGs participating in the modes identified in case 2020 are only Type 3, while for case 2022 they are only Type 4. This is specified in Table V. Moreover, participating Type 3 CCBGs are generic models operating in constant reactive control mode as shown in Fig. 1, and participating Type 4 CCBGs are generic models operating as described in Fig. 2.

TABLE V

SELECTED CCBG OSCILLATORY MODES

\begin{tabular}{c|c|ccccc}
\hline \hline Case & Mode & $\begin{array}{c}f \\
(\mathbf{H z})\end{array}$ & $\begin{array}{c}\zeta \\
(\boldsymbol{\%})\end{array}$ & CCBG PI* & $\begin{array}{c}\text { Number } \\
\text { of Areas }\end{array}$ & $\begin{array}{c}\text { CCBG } \\
\text { Type }\end{array}$ \\
\hline \multirow{2}{*}{2020} & 7 & 0.36 & 10.5 & $2.9 / 2.9$ & 2 & \\
\cline { 2 - 5 } & 8 & 0.37 & 11.51 & $\mathbf{4 . 3 / 8 . 6}$ & 4 & \\
\hline & 9 & 0.57 & 0.49 & $4.5 / 4.5$ & 1 & \\
\cline { 2 - 5 } 2022 & 10 & 0.57 & 3.63 & $10.8 / 10.8$ & 2 & 4 \\
\cline { 2 - 5 } & 11 & 0.59 & 6.85 & $4.5 / 4.5$ & 1 & \\
\cline { 2 - 5 } & 12 & 0.61 & 28.3 & $\mathbf{6 . 9 / 9 . 6}$ & 2 \\
\hline \hline
\end{tabular}

*The numerator and denominator in (8) are preserved and indicated in this column 
Two categories of CCBG oscillatory modes can be identified depending on whether additional synchronous machines participate in the mode or not. In Table V based on the CCBG PI defined in (8), a first class of CCBG oscillatory modes can be recognized where all the state variables participating in the mode are associated only with CCBGs. This is the case with modes 7, 9, 10 and 11. Under the selected criteria, a second category where there is also some participation of synchronous generators' state variables is also identified. In the studied WECC scenarios, the latter is a very uncommon class of modes and is manifested in modes 8 and 12 .

Tables VI and VII depict the state variable participation in modes 8 and 12. Fig. 3 shows the approximate location of the participating generators. Notice that mode 8 is an interarea mode involving a wide geographic region, even though there are only eight generators with participating factors greater than 0.1 in this mode. Also in Table VII, it is important to note that generators identified as $1 \mathrm{a}$ and $1 \mathrm{~b}$ are connected to a common bus, as is the case also for generators $5 \mathrm{a}$ and $5 \mathrm{~b}$.

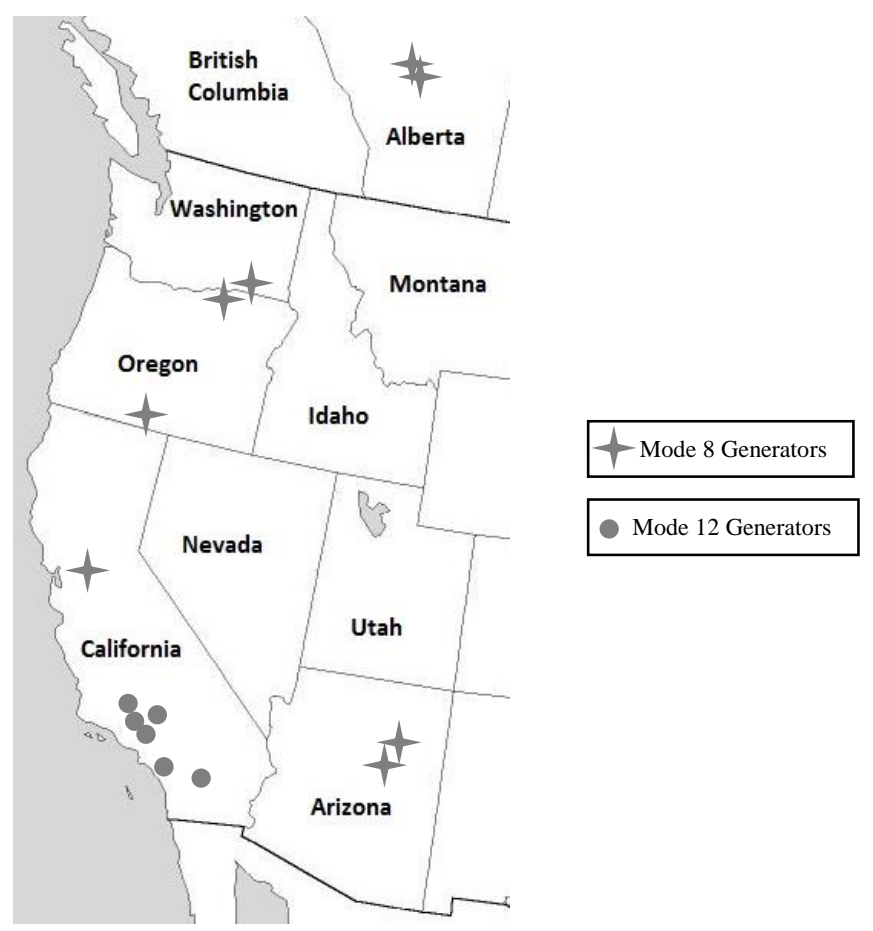

Fig. 3. Participating generators in the identified second class of CCBG oscillatory modes.

Observe that, the CCBG state variables participating in the two identified modes (8 and 12) are the reactive power generation $Q_{\text {gen }}$ and the voltage terminal magnitude $V_{\text {term }}$. They are affected mostly by the reactive power control integral gain $K_{\mathrm{qi}}$ and the voltage control integral gain $K_{\mathrm{vi}}$ in Type 4 generators, and their equivalents $K_{\mathrm{qi}}$ and $K_{\mathrm{qv}}$ in Type 3 generators. These gains are associated with control loops shown in Figs. 1 and 2, and described in [13].
TABLE VI

STATE VARIABLE PARTICIPATION IN MODE 8

\begin{tabular}{|c|c|c|c|c|c|c|}
\hline \multirow{2}{*}{ Area } & \multicolumn{2}{|c|}{ Generator } & \multirow{2}{*}{$\begin{array}{c}\text { Component } \\
\text { Model }\end{array}$} & \multirow{2}{*}{$\begin{array}{l}\text { Participation } \\
\text { Factor }\end{array}$} & \multirow{2}{*}{$\begin{array}{c}\text { Control } \\
\text { Parameter }\end{array}$} & \multirow{2}{*}{ State } \\
\hline & ID & Type & & & & \\
\hline \multirow{2}{*}{$\begin{array}{l}\text { North- } \\
\text { west }\end{array}$} & \multirow{2}{*}{1} & \multirow{2}{*}{3} & \multirow{2}{*}{$\begin{array}{c}\text { Converter } \\
\text { Control }\end{array}$} & 1 & $K_{\mathrm{qi}}$ & $Q_{\text {gen }}$ \\
\hline & & & & 0.859 & $K_{\mathrm{qv}}$ & $V_{\text {term }}$ \\
\hline \multirow{7}{*}{ 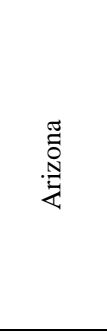 } & \multirow{7}{*}{2} & \multirow{7}{*}{ Sync } & Generator & 0.8198 & & $\omega$ \\
\hline & & & Generator & 0.7506 & & $\delta$ \\
\hline & & & Stabilizer & 0.545 & $T_{8}, T_{9}$ & $V_{\text {st }}$ \\
\hline & & & Generator & 0.3634 & & $\psi_{\mathrm{fd}}$ \\
\hline & & & Exciter & 0.3627 & & $E_{\mathrm{fd}}$ \\
\hline & & & Stabilizer & 0.3449 & $K_{\mathrm{s} 2}, T_{7}$ & $V_{\mathrm{st}}$ \\
\hline & & & Exciter & 0.2013 & $\begin{array}{l}K_{\mathrm{p}}, K_{\mathrm{i}}, \\
K_{\mathrm{d}}, T_{\mathrm{d}}\end{array}$ & $\mathrm{PID}_{\text {ou }}$ \\
\hline \multirow{2}{*}{ PG\&E } & \multirow{2}{*}{3} & \multirow{2}{*}{3} & \multirow{2}{*}{$\begin{array}{c}\text { Converter } \\
\text { Control }\end{array}$} & 0.4876 & $K_{\mathrm{qv}}$ & $V_{\text {term }}$ \\
\hline & & & & 0.4421 & $K_{\mathrm{qi}}$ & $Q_{\text {gen }}$ \\
\hline \multirow{2}{*}{ Arizona } & \multirow{2}{*}{4} & \multirow{2}{*}{3} & \multirow{2}{*}{$\begin{array}{c}\text { Converter } \\
\text { Control }\end{array}$} & 0.3043 & $K_{\mathrm{qv}}$ & $V_{\text {term }}$ \\
\hline & & & & 0.2903 & $K_{\mathrm{qi}}$ & $Q_{\text {gen }}$ \\
\hline \multirow{2}{*}{$\begin{array}{c}\text { North- } \\
\text { west }\end{array}$} & \multirow{2}{*}{5} & \multirow{2}{*}{3} & \multirow{2}{*}{$\begin{array}{c}\text { Converter } \\
\text { Control }\end{array}$} & 0.2544 & $K_{\mathrm{qv}}$ & $V_{\text {term }}$ \\
\hline & & & & 0.2464 & $K_{\mathrm{qi}}$ & $Q_{\text {gen }}$ \\
\hline \multirow{2}{*}{ Alberta } & \multirow{2}{*}{6} & \multirow{2}{*}{ Sync } & \multirow{2}{*}{ Generator } & 0.2538 & & $\omega$ \\
\hline & & & & 0.2147 & & $\delta$ \\
\hline \multirow{2}{*}{ Alberta } & \multirow{2}{*}{7} & \multirow{2}{*}{ Sync } & \multirow{2}{*}{ Generator } & 0.2504 & & $\omega$ \\
\hline & & & & 0.2119 & & $\delta$ \\
\hline \multirow{2}{*}{$\begin{array}{l}\text { North- } \\
\text { west }\end{array}$} & 8 & 3 & Converter & 0.2194 & $K_{\mathrm{qv}}$ & $V_{\text {term }}$ \\
\hline & 0 & & Control & 0.2147 & $K_{\mathrm{qi}}$ & $Q_{\text {gen }}$ \\
\hline
\end{tabular}

TABLE VII

State Variable Participation In MOde 12

\begin{tabular}{|c|c|c|c|c|c|c|}
\hline Area & $\begin{array}{l}\text { Gen } \\
\text { ID }\end{array}$ & $\begin{array}{r}\text { erator } \\
\text { Type }\end{array}$ & $\begin{array}{c}\text { Component } \\
\text { Model }\end{array}$ & $\begin{array}{l}\text { Participation } \\
\text { Factor }\end{array}$ & $\begin{array}{c}\text { Control } \\
\text { Parameter }\end{array}$ & State \\
\hline & \multirow{3}{*}{$1 \mathrm{a}$} & \multirow{3}{*}{4} & \multirow{3}{*}{$\begin{array}{c}\text { Converter } \\
\text { Control }\end{array}$} & 1 & $K_{\mathrm{gi}}$ & $Q_{\mathrm{gen}}$ \\
\hline & & & & 0.8404 & $K_{\mathrm{vi}}$ & $V_{\text {term }}$ \\
\hline & & & & 0.2483 & $T_{\mathrm{c}}$ & $Q_{\text {gen }}$ \\
\hline & \multirow{3}{*}{$1 b$} & \multirow{3}{*}{4} & \multirow{3}{*}{$\begin{array}{c}\text { Converter } \\
\text { Control }\end{array}$} & 1 & $K_{\mathrm{qi}}$ & $Q_{\text {gen }}$ \\
\hline & & & & 0.8404 & $K_{\mathrm{vi}}$ & $V_{\text {term }}$ \\
\hline & & & & 0.2483 & $T_{\mathrm{c}}$ & $Q_{\text {gen }}$ \\
\hline & ? & 4 & Converter & 0.5001 & $K_{\mathrm{qi}}$ & $Q_{\text {gen }}$ \\
\hline & 2 & 4 & Control & 0.4271 & $K_{\mathrm{vi}}$ & $V_{\text {term }}$ \\
\hline \multirow{6}{*}{ 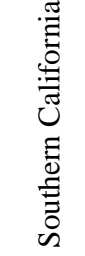 } & \multirow{2}{*}{3} & \multirow{2}{*}{4} & \multirow{2}{*}{$\begin{array}{c}\text { Converter } \\
\text { Control }\end{array}$} & 0.3003 & $K_{\mathrm{qi}}$ & $Q_{\text {gen }}$ \\
\hline & & & & 0.2552 & $K_{\mathrm{vi}}$ & $V_{\text {term }}$ \\
\hline & \multirow{2}{*}{4} & \multirow{2}{*}{4} & \multirow{2}{*}{$\begin{array}{c}\text { Converter } \\
\text { Control }\end{array}$} & 0.294 & $K_{\mathrm{qi}}$ & $Q_{\text {gen }}$ \\
\hline & & & & 0.2514 & $K_{\mathrm{vi}}$ & $V_{\text {term }}$ \\
\hline & \multirow{5}{*}{$5 \mathrm{a}$} & \multirow{5}{*}{ Sync } & Exciter & 0.4037 & & $E_{\mathrm{fd}}$ \\
\hline & & & Generator & 0.4036 & & $\psi_{\mathrm{fd}}$ \\
\hline \multirow[t]{8}{*}{$\downarrow$} & & & Generator & 0.2023 & & $\omega$ \\
\hline & & & Exciter & 0.1854 & $T_{\mathrm{c} 2}, T_{\mathrm{b} 2}$ & $E_{\mathrm{fd}}$ \\
\hline & & & Stabilizer & 0.1537 & $K_{\mathrm{s} 2}, T_{7}$ & $V_{\mathrm{st}}$ \\
\hline & \multirow{5}{*}{$5 b$} & \multirow{5}{*}{ Sync } & Exciter & 0.4018 & & $E_{\mathrm{fd}}$ \\
\hline & & & Generator & 0.4016 & & $\psi_{\mathrm{fd}}$ \\
\hline & & & Generator & 0.201 & & $\omega$ \\
\hline & & & Exciter & 0.1844 & $T_{\mathrm{c} 2}, T_{\mathrm{b} 2}$ & $E_{\mathrm{fd}}$ \\
\hline & & & Stabilizer & 0.1525 & $K_{\mathrm{s} 2}, T_{7}$ & $V_{\mathrm{st}}$ \\
\hline \multirow{2}{*}{$\begin{array}{l}\text { San } \\
\text { Diego }\end{array}$} & \multirow{2}{*}{6} & \multirow{2}{*}{4} & \multirow{2}{*}{$\begin{array}{c}\text { Converter } \\
\text { Control }\end{array}$} & 0.391 & $K_{\mathrm{qi}}$ & $Q_{\text {gen }}$ \\
\hline & & & & 0.336 & $K_{\mathrm{vi}}$ & $V_{\text {term }}$ \\
\hline
\end{tabular}


On the synchronous generators side, the participating state variables are the rotor angle $\delta$, the shaft speed $\omega$, the generator field voltage $E_{\mathrm{fd}}$, the generator flux linkage $\psi_{\mathrm{fd}}$ and the stabilizer output voltage $V_{\mathrm{st}}$. The control parameters related with the state variables in the stabilizer are the gain and time constants $K_{\mathrm{s} 2}$ and $T_{7}$ of the $P_{\text {gen }}$ input low-pass filter and the time constants $T_{8}$ and $T_{9}$ of the lead-lag ramp tracking filter. The stabilizer configuration for the three synchronous generators in Tables VI and VII is shown in Fig. 4 and it is based on the IEEE type PSS2A model described in [23]. Additionally, the parameters related with the exciter of the two synchronous generators participating in mode 12 , are the lead-lag time constants $T_{\mathrm{c} 2}$ and $T_{\mathrm{b} 2}$ in the main control loop of the automatic voltage regulator (AVR) of the exciter configuration model shown in Fig. 5 and based on the rotating excitation system REXS described in [23]. The exciter parameters of the synchronous generator 2 participating in Mode 8 are the proportional, integral and derivative gains $K_{\mathrm{p}}, K_{\mathrm{i}}$, and $K_{\mathrm{d}}$, as well as the derivative time constant $T_{\mathrm{d}}$ of the PID control block as described in [23] for type IEEE DC4B excitation systems.

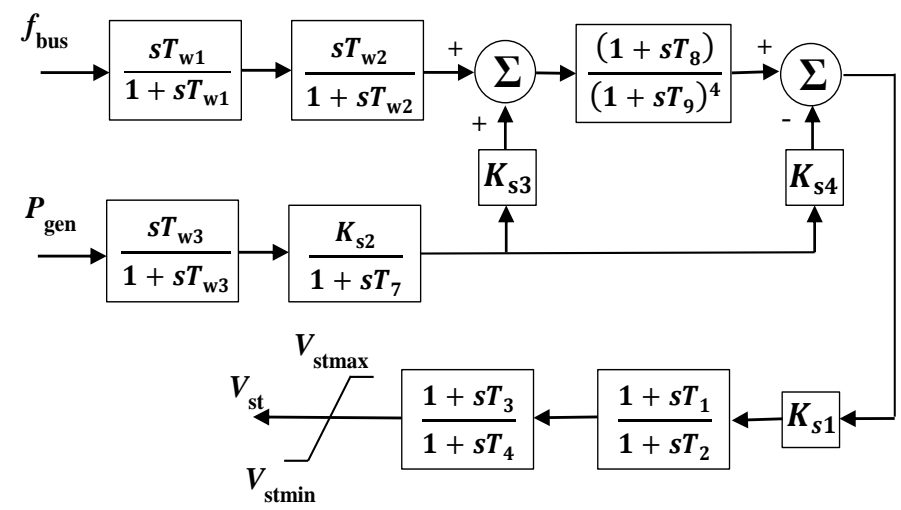

Fig. 4. Stabilizer control configuration in Tables VI and VII. The stabilizer is based on the IEEE type PSS2A model described in [23].

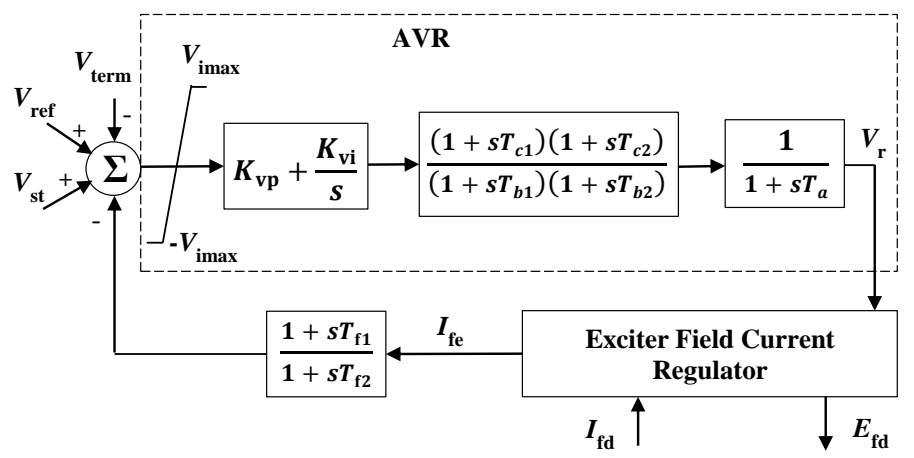

Fig. 5. Exciter control configuration in Table VII. The schematic is based on the rotating excitation system model REXS described in [23].

Due to the special characteristics of this second category of CCBG oscillatory modes, an examination of the mechanism of interaction between the state variables identified by the results obtained using SSAT [17] dealing with the interaction of the CCBG control state variables and the synchronous generators' control state variables was carried out using dynamic simulations in PSLF [23]. This simulation targets the excitation of modes 8 and 12 in the CCBGs by providing a pulse change in an interacting state variable of a dominant synchronous machine in the identified mode. In this experiment, a pulse of 0.2 pu and 0.5 seconds in the voltage reference was applied at the exciter of the most dominant synchronous generator in the associated mode in terms of participation factor. Then the $Q_{\text {gen }}$ response signals of some of the most dominant CCBGs together with the $Q_{\text {gen }}$ response of the involved synchronous generator are analyzed using multi-Prony analysis [24]. The selection of these signals is justified by the interaction between converter control state variables in CCBGs and exciter state variables in synchronous generators as shown in Tables VI and VII.

Fig. 6 shows the dynamic response of the three most dominant generators in mode 8 to a pulse change in the voltage reference of synchronous generator 2 in Table VI. The multi-Prony analysis of the three signals identifies mode 8 as one of the major components with a $0.31 \mathrm{~Hz}$ frequency and a damping ratio of $18.7 \%$ in the three responses. Table VIII shows the dominant modes identified by multi-Prony analysis for this case. These results substantiate the mechanism of the interaction and confirm that the pulse change in the voltage reference at the synchronous generator 2, excites the desired mode of oscillation and the interaction between the participating states in this mode also result in the mode being observed in the variables associated with the CCBGs identified as participating in the mode. A similar exercise was carried out for mode 12. Fig. 7 shows the dynamic response of some generators in mode 12 to a pulse change in the voltage reference of synchronous generator $5 \mathrm{a}$ in Table VII. Here, the modal identification analysis of the four signals estimated mode 12 with a frequency of $0.55 \mathrm{~Hz}$ with a damping ratio of $39.6 \%$. Table IX shows the dominant modes identified by the multi-Prony analysis for this case.
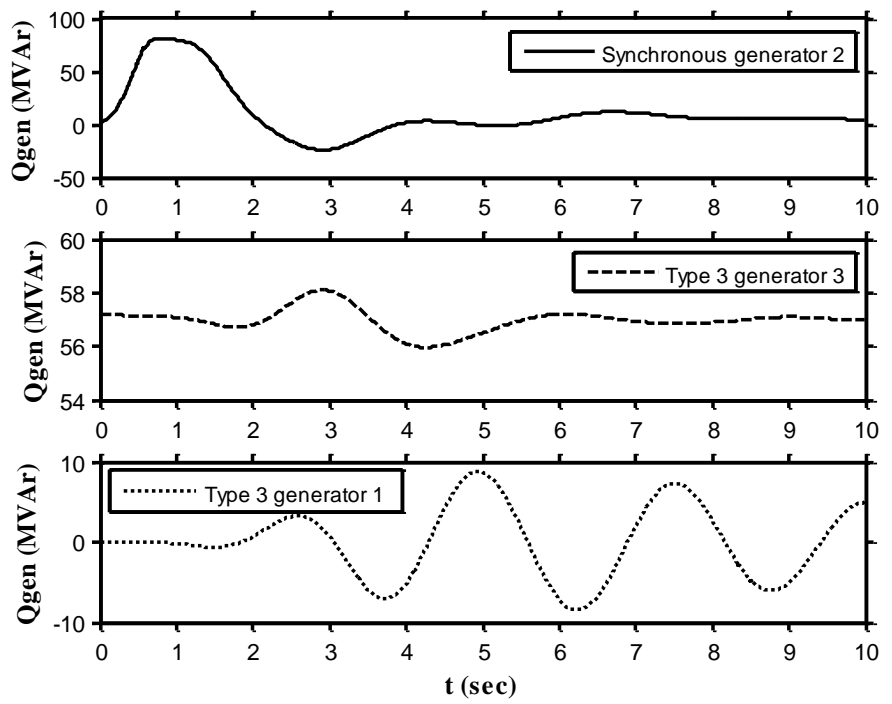

Fig. 6. Dynamic response of Mode 8 excited through the application of a pulse of 0.2 pu during $0.5 \mathrm{sec}$ to the reference voltage of the synchronous generator 2 in Table VI. The figure shows also the response of the two most dominant Type 3 CCBGs 
TABLE VIII

Multi-PRONy Results For Mode 8 Signals

\begin{tabular}{crrr}
\hline \hline \multicolumn{1}{c}{ Component } & Amplitude & \multicolumn{1}{l}{$\boldsymbol{l}(\mathbf{H z})$} & \multicolumn{1}{l}{$\boldsymbol{\zeta ( \% )}$} \\
\hline$-0.4098 \pm \mathrm{j} 1.1567$ & 21.2156 & 0.1841 & 33.3979 \\
$-0.3746 \pm \mathrm{j} 1.9659$ & 22.1955 & 0.3129 & 18.7178 \\
$-0.4108 \pm \mathrm{j} 3.6718$ & 14.2981 & 0.5844 & 11.1192 \\
$-1.5820 \pm \mathrm{j} 7.2386$ & 1.8901 & 1.1521 & 21.3506 \\
$-0.0372 \pm \mathrm{j} 2.5501$ & 1.0625 & 0.4059 & 1.4580 \\
$-0.7326 \pm \mathrm{j} 4.9819$ & 5.8569 & 0.7929 & 14.5488 \\
$-0.8914 \pm \mathrm{j} 12.2348$ & 2.4236 & 1.9472 & 7.2668 \\
$-0.2366 \pm \mathrm{j} 8.7837$ & 1.7194 & 1.398 & 2.6929 \\
\hline \hline
\end{tabular}

Only oscillatory components with amplitude greater than 1.0 are included.
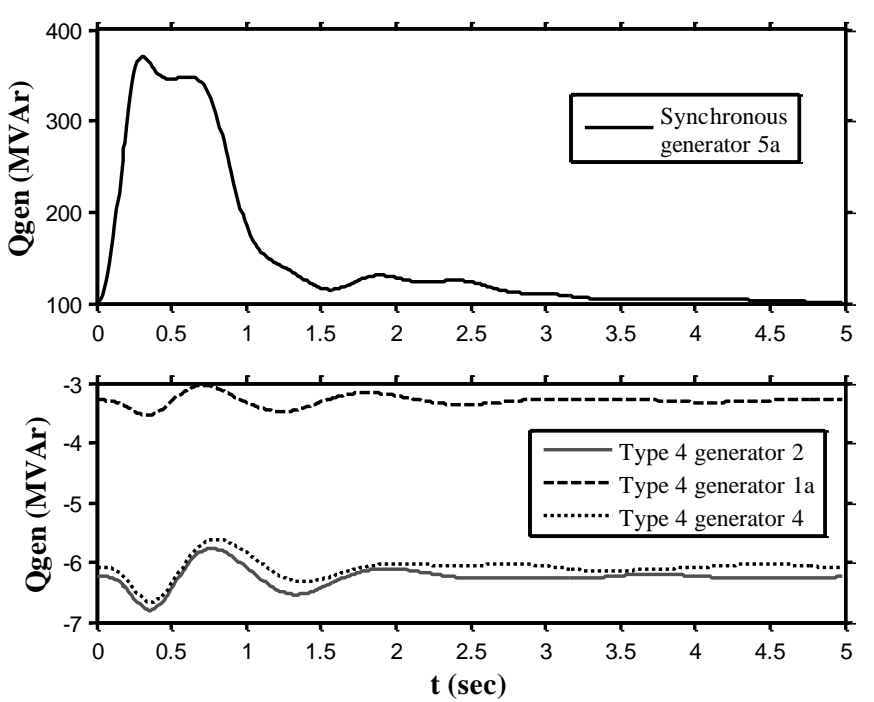

Fig. 7. Dynamic response of Mode 12 excited through the application of a pulse of $0.2 \mathrm{pu}$ during $0.5 \mathrm{sec}$ to the reference voltage of synchronous generator $5 \mathrm{a}$ in Table VII. The figure shows also the response of some of the most dominant CCBGs.

TABLE IX

Multi-Prony Results FOR Mode 12 Signals

\begin{tabular}{crcc}
\hline \hline \multicolumn{1}{c}{ Component } & Amplitude & $\boldsymbol{f}(\mathbf{H z})$ & $\zeta(\%)$ \\
\hline$-1.4955 \pm j 3.4661$ & 130.3420 & 0.5516 & 39.6172 \\
$-1.6451 \pm j 5.5772$ & 39.7493 & 0.8876 & 28.2916 \\
$-2.1744 \pm j 12.8847$ & 30.1976 & 2.0507 & 16.6403 \\
$-0.843 \pm j 11.0547$ & 9.7148 & 1.7594 & 7.6041 \\
$-0.828 \pm j 23.2939$ & 1.6736 & 3.7073 & 3.5525 \\
$-0.7367 \pm j 33.2057$ & 1.3500 & 5.2848 & 2.2180 \\
\hline \hline
\end{tabular}

$\overline{\text { Only oscillatory components with amplitude greater than } 1.0}$ are included.

The simulations verify the SSAT results by the excitation of the desired mode through a change in a reference signal asso- ciated with the most dominant synchronous generator and the multi-Prony analysis confirms that this same mode is observed in the identified variables associated with the participating CCBGs. As a result, the mechanism of interaction is also substantiated.

In Table $\mathrm{V}$, it can also be observed that the low frequency nature of the identified CCBG oscillatory modes is a common characteristic irrespective of whether these modes are local or interarea modes in terms of the location of the participating generators. This trait does not agree with the traditional concept of local and interarea modes [25], and it seems to be related with the high sensitivity of these modes to the control parameters in the CCBG control loops. With all the participating CCBGs operating with control configurations as described in Figs. 1 and 2 , the amplitude of the reactive power output control integral gain and the amplitude of the voltage control integral gain have the greatest impact on the frequency response of all these modes. The associated mode frequency and damping ratio depend heavily on these parameter values.

Table $\mathrm{X}$ shows the frequency and damping ratio sensitivities of the main modes identified in the planned 2022 case with respect to selected tuning parameters. The tuning parameters were selected based on the most dominant state. It is observed that based on the sensitivity magnitudes, the CCBG oscillatory modes have the highest sensitivities.

TABLE $\mathrm{X}$

Mode Sensitivities in CASE 2022

\begin{tabular}{ccccc}
\hline \hline Mode & $\begin{array}{c}\text { Dominant } \\
\text { State }\end{array}$ & $\begin{array}{c}\text { Tuning } \\
\text { Parameter }\end{array}$ & $\begin{array}{c}\text { Frequency } \\
\text { Sensitivity }\end{array}$ & $\begin{array}{c}\text { Damping } \\
\text { Sensitivity }\end{array}$ \\
\hline 1 & $\omega$ & $K_{\mathrm{PSS}}$ & $0.00 \%$ & $-0.05 \%$ \\
2 & $\omega$ & $K_{\mathrm{PSS}}$ & $-0.40 \%$ & $1.56 \%$ \\
4 & $\delta$ & $K_{\mathrm{PSS}}$ & $-0.03 \%$ & $-0.17 \%$ \\
5 & $\omega$ & $K_{\mathrm{PSS}}$ & $-0.49 \%$ & $5.37 \%$ \\
6 & $\delta$ & $K_{\mathrm{PSS}}$ & $0.12 \%$ & $-0.64 \%$ \\
\hline 9 & $Q_{\mathrm{gen}}$ & $K_{\mathrm{qi}}$ & $1.84 \%$ & $-83.70 \%$ \\
10 & $Q_{\mathrm{gen}}$ & $K_{\mathrm{qi}}$ & $2.55 \%$ & $-5.23 \%$ \\
11 & $V_{\text {term }}$ & $K_{\mathrm{vi}}$ & $1.51 \%$ & $6.41 \%$ \\
12 & $Q_{\text {gen }}$ & $K_{\mathrm{qi}}$ & $1.52 \%$ & $-2.48 \%$ \\
\hline \hline
\end{tabular}

Sensitivities are calculated based on a $10 \%$ increase of the tuning parameter.

In order to compare the impact of the tuning parameters in shaping the modal frequency characteristics of the electromechanical modes and CCBG oscillatory modes, two modes were selected from case 2022 to test the mode frequency and damping ratio excursions to variations in the most dominant control parameters. From the electromechanical mode's group, mode 5 with the highest sensitivities in this group is selected. In the CCBG mode's group, mode 12 with the lowest sensitivities in this group is selected. The variations in the tuning parameters 
are made proportional in both cases to their default values in order to obtain comparative results. Tables XI and XII present the obtained results.

TABLE XI

MODE 5 FreQUENCY SENSITIVITY TO TUNING PARAMETERS

\begin{tabular}{ccccc}
\hline $\begin{array}{c}\text { Tuning } \\
\text { Parameter }\end{array}$ & $\begin{array}{c}\text { Tuning } \\
\text { Value }\end{array}$ & $\boldsymbol{f}(\mathbf{H z})$ & $\zeta(\%)$ & $\begin{array}{c}\text { State Variable } \\
\text { Participation }\end{array}$ \\
\hline & $1.5(+50 \%)$ & 0.6539 & 17.02 & $1 / 12.45$ \\
& $1.1(+10 \%)$ & 0.6658 & 14.1 & $1 / 6.51$ \\
$K_{\text {PSS_1 }}$ & $\begin{array}{c}1.0(\text { Initial } \\
\text { conditions) }\end{array}$ & 0.669 & 13.39 & $1 / 10.21$ \\
Initial value $=$ & $0.8(-20 \%)$ & 0.6766 & 12.08 & $1 / 10.19$ \\
1.0 & $0.5(-50 \%)$ & 0.6924 & 10.83 & $1 / 13.82$ \\
& $0.3(-70 \%)$ & 0.7033 & 10.9 & $1 / 23.97$ \\
& $0.2(-80 \%)$ & 0.7074 & 11.16 & $0.71 / 23.78$ \\
$K_{\text {PSS_2 }}$ & $8.0(-20 \%)$ & 0.7075 & 10.93 & $1 / 24.75$ \\
Initial value $=$ & $5.0(-50 \%)$ & 0.708 & 10.6 & $1 / 27.20$ \\
10 & $2.0(-80 \%)$ & 0.709 & 10.28 & $0.97 / 29.61$ \\
& $0.5(-95 \%)$ & 0.7094 & 10.11 & $0.93 / 30.40$ \\
\hline $\begin{array}{c}K_{\text {PSS_3 }} \\
\text { Initial value }=\end{array}$ & $8.0(-20 \%)$ & 0.71 & 9.87 & $0.99 / 32.01$ \\
10 & $2.0(-80 \%)$ & 0.712 & 9.15 & $0.77 / 31.57$ \\
\hline \hline
\end{tabular}

TABLE XII

Mode 12 FREQUENCY SENSITIVITY TO TUNING PARAMETERS

\begin{tabular}{ccccc}
\hline \hline $\begin{array}{c}\text { Tuning } \\
\text { Parameter }\end{array}$ & $\begin{array}{c}\text { Tuning } \\
\text { Value }\end{array}$ & $f(\mathbf{H z})$ & $\zeta(\%)$ & CCBG PI \\
\hline & $\begin{array}{c}0.1 \text { (Initial } \\
\text { conditions) }\end{array}$ & 0.6069 & 28.28 & $6.93 / 9.62$ \\
& $0.11(+10 \%)$ & 0.6161 & 27.58 & $6.36 / 6.99$ \\
$K_{\text {qi_la }}$ & $0.12(+20 \%)$ & 0.6246 & 26.52 & $6.00 / 6.00$ \\
Initial value $=$ & $0.13(+30 \%)$ & 0.6315 & 25.25 & $5.96 / 5.96$ \\
0.1 & $0.14(+40 \%)$ & 0.6364 & 23.82 & $6.05 / 6.05$ \\
& $0.15(+50 \%)$ & 0.6383 & 22.35 & $6.38 / 6.38$ \\
& $0.2(+100 \%)$ & 0.6208 & 19.55 & $7.96 / 7.96$ \\
& $0.25(+150 \%)$ & 0.6122 & 19.56 & $7.14 / 7.14$ \\
$K_{\mathrm{qi}} 2$ & $0.12(+20 \%)$ & 0.6409 & 17.76 & $6.7 / 6.7$ \\
Initial value $=$ & $0.14(+40 \%)$ & 0.6569 & 14.14 & $6.05 / 6.05$ \\
0.1 & $0.2(+100 \%)$ & 0.6226 & 11.48 & $4.69 / 4.69$ \\
\hline $\begin{array}{c}K_{\mathrm{qi}} \text { 1b } \\
0.1\end{array}$ & $0.12(+20 \%)$ & 0.6692 & 5.71 & $2.64 / 2.64$ \\
& $0.13(+30 \%)$ & 0.6992 & 2.95 & $2.54 / 2.54$ \\
\hline \hline & $0.14(+40 \%)$ & 0.7222 & 0.46 & $2.69 / 2.69$ \\
\hline \hline
\end{tabular}

Table XI shows the electromechanical interarea mode 5's sensitivity to variations in the PSS' control gains associated with the most dominant state variables in this mode. At initial con- ditions the tuning parameter is the PSS's control gain of the most dominant generator $K_{\mathrm{PSS} \_}$. As seen in Table XI, this value is increased up to $50 \%$ and decreased up to $80 \%$. At the lowest value, the associated state variable with $K_{\mathrm{PSS}_{-1}}$ is no longer the most dominant state. At this point the PSS control gain associated with the new most dominant generator is $K_{\mathrm{PSS} \_2}$, the initial value is 10 and this value is decreased through different steps up to $95 \%$. At these operating conditions, $K_{\mathrm{PSS} \_3}$ becomes the PSS control gain of the most dominant generator and it is decreased up to $80 \%$. Notice that the excursions in the mode's frequency range from 0.6539 to $0.712 \mathrm{~Hz}$, correspondingly the damping ratio changes. However, there is no significant drop in the damping ratio and the mode remains stable for the range of parameter variations considered.

On the other hand, Table XII shows frequency sensitivity of the CCBG oscillatory mode 12 to variations of the reactive power output integral gains associated with the most dominant generators. Here three different tuning parameters are chosen associated with the most dominant state variable at each stage, as explained above for Table XI. Note that in this table the CCBG PI has been included. Based on this index, the participation of synchronous generators disappears after the parameter $K_{\text {qi_la }}$ has been decreased by $20 \%$ and the frequency characteristics of the mode have changed. For mode 12, the frequency excursion ranges from 0.6069 to $0.7222 \mathrm{~Hz}$ for parameter variations considered. It should be noted however, that for mode 12 there is a significant drop off in damping ratio for allowable range of excursions in the sensitivity parameter. The drop off in damping ratio is significant and points to the fact that care would have to be taken to appropriately tune the associate parameters.

\section{CONCLUSIONS}

A universally accepted model based small signal stability analysis has been used to determine the impact of a projected increasing level of CCBGs in a large-scale power system, such as the Western Interconnection.

It has been determined the relative low interaction between CCBG generic models and synchronous generators in the traditional interarea electromechanical modes. It has been shown that Type 3 and Type 4 CCBGs operating under the control configurations specified in Figures 1 and 2 may participate in these modes with the reactive power control integral gains and the voltage control integral gains. Based on the low participation of CCBGs operating under the described conditions, it can be concluded that the changes in frequency response of the traditional electromechanical interarea modes through the different test bed cases are not a direct consequence of CCBG control actions.

Two new varieties of oscillatory modes dominated by CCBGs have been described. The first category is dominated exclusively by CCBGs of only one type and the second category occurs with additional interaction with the synchronous gener- 
ators through control loops. Evidence in the frequency domain of the interaction between CCBGs and synchronous machines through their control loops in this second category of uncommon modes, is presented in Tables VI and VII. Dynamic simulations in conjunction with modal signal identification techniques validate the results.

A comparative analysis between the traditional electromechanical interarea modes and the identified CCBG oscillatory modes is presented throughout the sections. One of the highlights of the new CCBG oscillatory modes is their high sensitivity to control parameter variations, which can lead to the following potential implications:

1. Dramatic changes in CCBG mode shapes in response to changes in the tuning parameters that can make the system more unpredictable and hard to monitor and control.

2. CCBGs local low frequency oscillations akin to interarea electromechanical oscillations may affect the observability of some interarea electromechanical modes.

3. Few control parameters can significantly improve mode damping but also create unstable modes if not tuned properly.

\section{REFERENCES}

[1] J. Quintero, V. Vittal, G. T. Heydt, H. Zhang and B. Nickell, "Security assessment of the year 2020 planned western interconnection," IEEE PES General Meeting, Vancouver, BC, July 2013.

[2] L. Fan, H. Yin and Z. Miao, "On active / reactive power modulation of DFIG-based wind generation for interarea oscillation damping," IEEE Trans. on Energy Convers., vol. 26, no. 2, pp. 513 - 521, June 2011.

[3] S. Eftekharnejad, V. Vittal, G.T. Heydt, B. Keel, J. Loehr, "Impact of increased penetration of photovoltaic generation on power systems," IEEE Trans. on Power Syst., vol. 28, no. 2, pp. 893 - 901, May 2013.

[4] D. Gautam, V. Vittal and T. Harbour, "Impact of increased penetration of DFIG-based wind turbine generators on transient and small signal stability of power systems," IEEE Trans. on Power Syst., vol. 24, no. 3, pp. 1426 - 1434, Aug. 2009.

[5] S. Q. Bu, W. Du, H. F. Wang, Z. Chen, L. Y. Xiao and H. F. Li, "Probabilistic analysis of small-signal stability of large-scale power systems as affected by penetration of wind generation," IEEE Trans. Power Syst. vol. 27, no. 2, pp. $762-770$, May 2012.

[6] T. Knüppel, J. N. Nielsen, K. H. Jensen, A. Dixon and J. Østergaard, "Small-signal stability of wind power system with full-load converter interfaced wind turbines," IET Renewable Power Generation, vol. 6, No. 2, pp. 79-91, 2012.

[7] F. Mei and B. Pal, "Modal analysis of grid-connected doubly fed induction generators," IEEE Trans. on Energy Convers., vol. 22, no. 3, pp. 728 736, Sept. 2007.

[8] J. J. Sanchez-Gasca, N. W. Miller and W. W. Price, "A modal analysis of a two-area system with significant wind power penetration," Proc. IEEE Power Syst. Conf. Expo., vol. 2, pp. 1148 - 1152, Oct. 2004.

[9] G. Tsourakis, B. M. Nomikos and C. D. Vournas, "Contribution of doubly fed wind generators to oscillation damping," IEEE Trans. on Energy Convers., vol. 24, no. 3, pp. 783 - 791, Sept. 2009.

[10] J. Morató, T. Knüppel and J. Østergaard, "Residue-based evaluation of the use of wind power plants with full converter wind turbines for power oscillation damping control,” IEEE Trans. Sustainable Energy, vol. 5, No. 1, pp.82-89, January 2014.

[11] D. Gautam, L. Goel, R. Ayyanar, V. Vital and T. Harbour, "Control strategy to mitigate the impact of reduced inertia due to doubly fed induction generators on large power systems," IEEE Trans. Power Syst., vol. 26, no. 1, pp. 214 -224, Feb. 2011.
[12] R. D. Fernandez, R. J. Mantz and P. E. Battaiotto, "Contribution of wind farms to the network stability," Proc. IEEE PES General Meeting, Montreal, Que., 2006.

[13] A. Ellis, Y. Kazachkov, E. Muljadi, P. Pourbeik, and J. J. Sanchez-Gasca, "Description and technical specifications for generic WTG models - a status report," IEEE/PES Power Systems Conference and Exposition, pp. 1-8, Phoenix, AZ, 2011.

[14] K. Clark, N. W. Miller and J. J. Sanchez-Gasca, Modeling of GE wind turbine-generators for grid studies, ver. 4.5, Schenectady NY, April 2010.

[15] N. W. Miller, R. Walling, M. Shao and J. MacDowell, Modeling of GE photovoltaic plants for grid studies, ver. 1.2, Schenectady NY, May 2011.

[16] D. Kosterev, A. Meklin, J. Undrill, B. Lesieutre, W. Price, D. Chassin, R. Bravo, and S. Yang, "Load modeling in power system studies: WECC progress update," Proc. IEEE PES General Meeting, July 2008.

[17] Powertech, Small Signal Analysis Tool: User Manual, Surrey, BC, 2012.

[18] H. K. Hassan, Nonlinear Systems, 3rd ed. Upper Saddle River, NJ: Prentice Hall, 2001.

[19] C.-T. Chen, Linear System Theory and Design, $3^{\text {rd }}$ ed. New York: Oxford University Press, 1999.

[20] N. Martins, "Efficient eigenvalue and frequency response methods applied to power system small-signal stability studies," IEEE Trans. on Power Syst., vol. 1, no. 1, pp. 217 - 224, Feb. 1986.

[21] IEEE PES, Eigenanalysis and frequency domain methods for system dynamic performance, New York NY, 1989.

[22] I. J. Pérez-Arriaga, G. C. Verghese, and F. C. Schweppe, "Selective modal analysis with applications to electric power systems, Part I: Heuristic introduction," IEEE Trans. on Power Apparatus and Systems, vol. 101, pp. 3117-3125, Sep. 1982.

[23] GE Concorda, PSLF Users' Manual, ver. 18, Schenectady NY, Oct. 2012.

[24] D. J. Trudnowski, J. M. Johnson, and J. F. Hauer, "SIMO system identification from measured ringdowns," Proc. American Control Conf., pp. 2968-2972, 1998.

[25] G. Rogers, Power System Oscillations, 1st ed. New York: Springer, 2000.

\section{BIOGRAPHIES}

Jaime Quintero (M'06) received his Ph.D. degree in electrical engineering from Washington State University, Pullman, WA, in 2005. He is on leave as an Associate Professor from Universidad Autónoma de Occidente, Cali, Colombia. Currently, he is a postdoctoral researcher at Arizona State University, Tempe, AZ.

Vijay Vittal (S'78-F'97) received the Ph.D. degree from Iowa State University, Ames, IA, in 1982. He is currently the Director of the Power Systems Engineering Research Center (PSERC) and is the Ira A. Fulton Chair Professor in the Department of Electrical Engineering at Arizona State University, Tempe. Dr. Vittal is a member of the National Academy of Engineering.

Gerald T. Heydt (S'62-M'64-SM'80-F'91-LF'08) is from Las Vegas, NV. He received the $\mathrm{Ph} . \mathrm{D}$. degree in electrical engineering from Purdue University, West Lafayette, IN, in 1970. Dr. Heydt is a member of the National Academy of Engineering. Currently, he is the Site Director of PSERC at Arizona State University in Tempe where he is a Regents' Professor.

Hui Zhang (S'09) is from Nanjing, China. He received the B.S. degree from Hohai University, Nanjing, China, in 2008 and the M.S. degree from Arizona State University, Tempe, in 2010, both in electrical engineering. He is currently pursuing the Ph.D. degree at Arizona State University. Hui Zhang is a research associate at Arizona State University. 